\title{
Supratentorial cerebral cavernous malformations: clinical, surgical, and genetic involvement
}

\author{
Vincenzo Antonio D’Angelo, M.D., Costanzo De Bonis, M.D., Rosina Amoroso, M.D., \\ Alessandro Calì, M.D., Leonardo D’Agruma, M.Sc., Vito Guarnieri, M.Sc., \\ Lucia Anna Muscarella, M.Sc., Leopoldo Zelante, M.D., Michele Bisceglia, M.D., \\ Tommaso Scarabino, M.D., AND Domenico CataPano, M.D. \\ Neurosurgical Operative Unit, Medical Genetic Service, Pathology Service, and Radiology Service, \\ "Casa Sollievo della Sofferenza” Hospital, San Giovanni Rotondo, Italy
}

\begin{abstract}
Object. Although there is general agreement on the methods of treatment for symptomatic supratentorial cerebral cavernous malformations (CMs) located in noneloquent areas, some controversy exists regarding the management of cerebral CMs that are asymptomatic and/or located in eloquent or deep areas. Moreover, recent advances in genetic findings could influence both standard clinical management and the follow-up strategy in affected individuals. Thus, the objective of this study was to develop, based on the authors' experience and a literature review, a management algorithm to deal with supratentorial cerebral CMs.

Methods. The authors retrospectively reviewed the clinical data related to 118 patients who underwent surgery for symptomatic supratentorial cerebral CMs at their institution. Twenty-eight of 118 patients harbored multiple lesions, and nine of these 28 patients had a clinically positive familial history. Genetic investigations were performed in 89 patients $(75 \%)$.

Conclusions. Surgery for supratentorial cerebral CMs in noneloquent locations is safe and curative. In cerebral CMs located in deep and eloquent areas and with symptoms including progressive neurological deficits, evidence of hemorrhage, and uncontrolled seizures, surgical treatment according to an integrated plan based on frameless stereotactic guidance and functional magnetic resonance imaging is recommended and results in acceptably low morbidity. The data support the need for long-term imaging follow up in all patients, careful preoperative vascular studies to detect associated venous anomalies, and the importance of genetic mutational analysis. The DNA screening protocol will change the care of family members of patients with familial forms of cerebral CMs, because affected asymptomatic family members may benefit by early detection of lesions. At the same time, the exclusion of family members who are not carriers of the mutation as members of the population at risk reduces the economic and psychological burden of clinical and instrumental monitoring.
\end{abstract}

\section{KEY WORDS • cerebral cavernoma • hemorrhage • vascular malformation}

cavernous angioma • management algorithm •

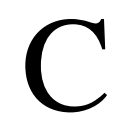

EREBRAL CMs are angiographically cryptic lesions that are classically defined by enlarged and thinwalled vascular structures in the central nervous system without intervening brain parenchyma. These malformations are lined by endothelial cells and lack supporting vascular smooth-muscle cells, and they are surrounded by hemosiderin deposits and gliosis, which may or may not be thrombosed..$^{53}$ On gross examination, they appear as berry-like, reddish-purple lesions that are variable in size (ranging from $1 \mathrm{~mm}$ to several centimeters), multiple or single, often encapsulated and multilobar, containing hemorrhage in various stages of organization, and occasionally calcified. . $^{33,34,44,51}$

The true prevalence of cerebral CMs in the general population is unknown. These lesions have been found in up to $0.5 \%$ of the population in large autopsy and MR imag-

Abbreviations used in this paper: $\mathrm{CM}=$ cavernous malformation; $\mathrm{fMR}=$ functional magnetic resonance. ing series. ${ }^{13,40,50}$ The clinical presentation of these lesions is highly variable, ranging from an incidental finding at neuroimaging to discovery during autopsy after a fatal hemorrhage..$^{29}$ The most common symptoms of CMs are seizure disorders (possibly caused by the toxic effects of iron deposition), followed by focal neurological deficits and headache..$^{20,59}$

In virtually all CMs, there are signs of repeated microhemorrhage on neuroimaging, even if clinically significant hemorrhage is a less common phenomenon (with an annual risk at 0.25 to $6 \%$ ), and the incidence of microhemorrhages increases after the first episode. . $^{1,13,22,23,41,42,49,62}$ Nevertheless, this level of risk, if we consider it over a lifetime in young patients and in the few cases in which massive fatal hemorrhage has occurred, is not insignificant. ${ }^{24,30,31,34}$ The MR imaging modality is the diagnostic tool of choice because of its high sensitivity and specificity in detecting the hemoglobin degradation products present inside and around the lesion. ${ }^{16,19,36,46,47,52,58}$

Cerebral CMs can be found in every region of the cen- 
tral nervous system, and the supratentorial location is represented in almost 70 to $80 \%$ of intracranial cases, with multiple lesions in 10 to $20 \%$ of patients. ${ }^{5,13,23,29,48} \mathrm{Al}$ though cerebral CMs were once considered to be a developmental disorder, several authors have reported their de novo appearance, mostly after radiation therapy., $40,15,27,34$, 56,62 Cerebral cavernous angiomas can occur in a sporadic or autosomal-dominant inherited form, with familial cases often characterized by the presence of multiple lesions, whereas patients in nonfamilial cases usually harbor only a single malformation. ${ }^{25,48}$

Although there is general agreement on the method of treatment for symptomatic supratentorial cerebral CMs located in noneloquent areas, some controversy exists about the management of asymptomatic lesions and malformations located in eloquent or deep areas. Moreover, recent advances in genetic findings could influence both standard clinical management and the follow-up strategy in affected individuals. ${ }^{25,45}$ Thus, the goal of this study was to develop, based on our experience and a literature review, a management algorithm to deal with supratentorial cerebral CMs.

\section{Clinical Material and Methods}

\section{Patient Population}

We retrospectively reviewed the clinical data related to 118 patients who underwent surgery for symptomatic supratentorial cerebral CMs at our institution between January 1992 and August 2005. The patients' ages ranged from 19 months to 90 years (mean 39 years), and the male/female ratio was 1.8:1. The mean follow-up duration was 55 months (range 8-164 months).

\section{Number and Characteristics of Lesions}

We removed 125 cerebral CMs: 90 in patients with single lesions and 35 in a group of 28 patients with multiple cavernomas. In this latter group, nine patients had a positive familial history for cerebral CMs.

The size of the cavernomas ranged from 4 to $60 \mathrm{~mm}$ (mean $26 \mathrm{~mm}$ ). One hundred ten of 125 cerebral CMs were lobar (cortical-subcortical and deep white matter), with 49 of 110 lesions located in eloquent areas. Fifteen of 125 cerebral CMs were deep seated (lateral ventricles, corpus callosum, thalamus, basal ganglia).

\section{Clinical Presentation}

The main clinical presentation included epilepsy (69 patients), focal neurological deficits (37), raised intracranial pressure (six), and chronic headaches (six). Clinical symptoms related to hemorrhage were acute or subacute in 43 cases and chronic in six. Hemorrhage, which was present in $38 \%$ of patients, was intralesional in six cases, extralesional in 35, and intra/extralesional in two. In two other patients, subarachnoid hemorrhage was observed in association with an extralesional hemorrhage. The size of the hemorrhage was less than $2 \mathrm{~cm}$ in 25 lesions and more than $2 \mathrm{~cm}$ in 20 . Six cavernomas contained a capsulated hemorrhage.

Seizures, which were present in $69(58 \%)$ of the patients, were of the following types: generalized tonic clon- ic in 10 patients (14\%), generalized tonic clonic with focal onset in $11(16 \%)$, simple partial type in $28(41 \%)$, and complex partial in $20(29 \%)$. The duration of epilepsy history was less than 6 months in 45 patients $(65 \%)$ and more than 6 months in $24(35 \%)$. The Engel classification ${ }^{17}$ (Table 1) was used to evaluate postoperative seizure outcome.

\section{Neuroimaging Studies}

A 3-tesla fMR imaging unit was used in 10 patients for motor strip identification, whereas cerebral digital subtraction angiography was performed for identification of associated vascular anomalies in 56 patients with hemorrhage or lesions located in deep or eloquent areas.

\section{Surgical Procedures}

Surgery was performed within 10 days in patients presenting with acute intra/extralesional hemorrhage. The surgical approach was transcortical in 102 cavernomas, transsulcal in 17, and interhemispheric-parasplenial in six. In 39 patients with subcortical, central region, or deep-seated cavernomas, intraoperative anatomical guidance was provided with the aid of a neuronavigational system (VectorVision; BrainLAB USA, Inc., Moorestone, NJ). Intraoperative neurophysiological mapping was performed in 10 patients and integrated fMR imaging with neuronavigation in five, all with lesions located in eloquent areas.

\section{Genetic Studies}

Genetic studies were performed in 89 patients $(75 \%)$, as follows: the group of nine patients with a family history of cerebral CMs, all of whom were harboring multiple lesions; a group of 18 patients harboring multiple lesions in whom there was no family history of cerebral CMs; and a group of 62 patients with single, apparently sporadic lesions, but in whom the family history either was not complete or was not suggestive of possible cerebral CMs (that is, seizures, cerebral hemorrhage of unknown cause, and so on).

\section{Statistical Analysis}

The data were statistically analyzed using the chisquare test. The Fisher exact probability test was used when there were fewer than four variables. The level of statistical significance was set below 0.05 .

\section{Results}

No significant difference in the incidence of CMs was found among the various age groups or according to sex. Developmental venous anomalies were identified on angiographic studies in 41 (73\%) of 56 patients. The anomalies designated as venous angioma and distinguished from angiomas that were "venous-like" were present in 19 patients (34\%), with 12 anomalies adjacent (Fig. 1) and seven distant to the cavernoma (Fig. 2). Other venous anomalies included hypertrophic veins, thrombosed veins, and hypoplastic or thrombosed sinus (present in 22 cases [39\%], with 11 anomalies adjacent and 11 distant to the cavernoma); capillary blush in three cases $(5 \%)$, arterial afferent in two cases (3\%), other vascular lesions in two 
TABLE 1

Engel classification*

\begin{aligned} & \hline \hline Class \multicolumn{1}{c}{ Criteria } \\ & \hline I free of disabling seizures \\ & II rare disabling seizures, "almost seizure free" \\ & III worthwhile improvement \\ & IV no worthwhile improvement \\ & \hline\end{aligned}

* According to the scale published by Engel, et al., in 1993.

cases $(3 \%)$, one arteriovenous malformation, and one aneurysm.

Radical lesionectomy was performed in 124 lesions (99\%), with a one-stage double lesionectomy in seven patients. Partial resection was performed in one cavernoma located in the thalamus. A gliotic hemosiderin ring was totally resected in 61 cerebral CMs, all of them located in cortical-subcortical noneloquent areas.

There were no surgery-related deaths in this series. In 78 patients $(66 \%)$ the neurological condition remained unchanged after surgery, whereas 30 patients $(25 \%)$ presented with clinical improvement. The neurological condition deteriorated in three patients $(2.5 \%)$ after surgery, all with postoperative complications: one patient had an intraparenchymal hematoma secondary to removal of an associated venous angioma, which required no treatment; one patient who underwent evacuation of hematoma from the residual cavernoma; and one who underwent removal of a basal ganglia cerebral CM and who suffered from postoperative ischemia at the site of surgery. Other postoperative complications were as follows: one extradural hematoma, which required no treatment; one case of pulmonary embolism; and two cases of deep venous throm- bosis. The patients remained in the intensive care unit for 1 to 6 days after surgery, and the mean hospital stay was 7 days.

No neurological deficit was found at follow-up evaluation in $80 \%$ of patients, a moderate neurological deficit was found in $13 \%$, and severe deficit in $7 \%$. Patients with moderate and severe disability had lesions located in eloquent or deep cerebral areas.

At follow-up examination in the 69 patients suffering from preoperative seizure disorders, $57(82 \%)$ were in Class I, six $(9 \%)$ were in Class II, four $(6 \%)$ were in Class III, and two (3\%) were in Class IV, according to the Enge ${ }^{17}$ classification (Table 1), with a significant correlation between a seizure history shorter than 6 months and better outcome after epilepsy surgery (Table 2 ). The correlation between simple lesionectomy with or without removal of the hemosiderin gliotic ring and postoperative outcome in patients with epilepsy was not significant. A second-stage additional amygdalohippocampectomy was performed in one patient for uncontrolled seizures, with subsequent control. On the last follow-up imaging session, two recurrences were revealed adjacent to the resected cavernoma.

In 13 patients, a de novo development of cerebral CMs distant from the initial lesion was discovered: in 12 of 13 patients from the group with clinically and/or genetically confirmed familial cerebral CMs, and in one of 10 patients from the group with sporadic lesions. Genetic studies resulted in the following findings: seven mutations (78\%) in the group of nine patients with a positive family history and multiple cerebral CMs; 12 mutations $(66 \%)$ in a group of 18 patients harboring multiple lesions with no family history of cerebral CMs; and two mutations (3\%) in the group of 62 patients with a single, apparently sporadic lesion. To date, DNA analysis in family members


FIG. 1. Left: Axial MR image showing a right temporal cavernous angioma. Right: Angiographic study demonstrating an associated adjacent venous angioma-like lesion (arrows). 
TABLE 2

Correlation between preoperative duration of seizure history and postoperative seizure outcome

\begin{tabular}{ccc}
\hline \hline & \multicolumn{2}{c}{ Preop Seizure History* } \\
\cline { 2 - 3 } Postop Engel Class & No. (\%) w/ $\leq 6 \mathrm{Mos}$ & No. $(\%) \mathrm{w} />6$ Mos \\
\hline I & $41(91)$ & $16(66)$ \\
II & $3(7)$ & $3(12)$ \\
III & $1(2)$ & $3(12)$ \\
IV & 0 & $2(8)$ \\
\hline
\end{tabular}

* In 45 patients the preoperative duration of seizure history was 6 months or less, and in 24 patients it was more than 6 months.

has shown 40 carriers of the mutation, 19 of them harboring asymptomatic cerebral CMs at the time of MR imaging examination.

\section{Discussion}

There is general agreement in recommending surgery for symptomatic supratentorial cerebral CMs that are not located in deep or eloquent areas. In these cases, surgery is generally safe and its efficacy is established both for control of epilepsy and prevention of rebleeding, whereas controversy exists about resection of cerebral CMs located in critical areas in patients with few or no symptoms. ${ }^{5,6}$, $29,35,55,62$

In agreement with other authors, we found that supratentorial cerebral CMs, including those in critical areas, can be microsurgically treated with a favorable risk/benefit ratio by using, on a case-by-case basis, frameless stereotactic guidance, electrophysiological monitoring, and/or integrated neuronavigation with fMR imaging. $2,28,29,32,38,45$

The epileptogenicity of cavernomas has been ascribed to the ongoing deposition of iron and blood breakdown products..$^{26,48}$ We were unable to detect a significant relationship between a postoperative hemosiderin ring and seizure outcome. In our series, lesionectomy alone with or without resection of the gliotic hemosiderin ring accom- plished good seizure control in the majority of patients with epilepsy, and there was a significant correlation of good outcome with a shorter seizure history (Table 2), in agreement with other authors. . $^{3,8,9,11,18,37}$ In some cases of mesial temporal cavernomas with chronic or partially controlled seizures, the use of intraoperative electrocorticography may help us decide whether to perform further resection - that is, amygdalohippocampectomy or standard anterior temporal lobectomy. We performed additional amygdalohippocampectomy in a second stage in a patient with poor seizure control after a complete pure cavernoma resection. As reported, $, 5,73$ and in agreement with our experience, resection of associated venous anomalies contiguous to the cavernoma could be dangerous and should be avoided.

In our series, routine MR imaging follow-up studies revealed two recurrences of the resected cerebral CMs in adjacent locations and 13 distant de novo cerebral CMs, mostly in familial forms. None of these patients had undergone radiation therapy, nor had they suffered viral infections during the follow-up period. In agreement with other authors, ${ }^{15}$ we believe that this discovery may lead to an upward revision in risk estimates, because hemorrhage risk per annum has traditionally been calculated since birth. Therefore, we emphasize the need for long-term imaging follow up, mostly in familial cases.

Genetic factors have been identified in 20 to $30 \%$ of patients with CMs. ${ }^{20,48}$ Familial cases are often characterized by the presence of multiple lesions, whereas sporadic cases usually entail only a single malformation. ${ }^{25,48}$ In familial cases, the clinical symptoms denoting penetrance are not always present, and it has been suggested that this might depend on the gene causing the cerebral CMs and on the patient's age at onset. ${ }^{12,14}$ However, in other reports, it has been suggested that up to $75 \%$ of the so-called sporadic cases with multiple lesions are, in reality, familial cases, with asymptomatic vascular lesions in relatives masking the autosomal-dominant segregation pattern. ${ }^{25}$ Based on MR screening studies, in familial cases, penetrance is age-dependent and approaches $100 \%$ in affected adults, even if only approximately $60 \%$ of those affected

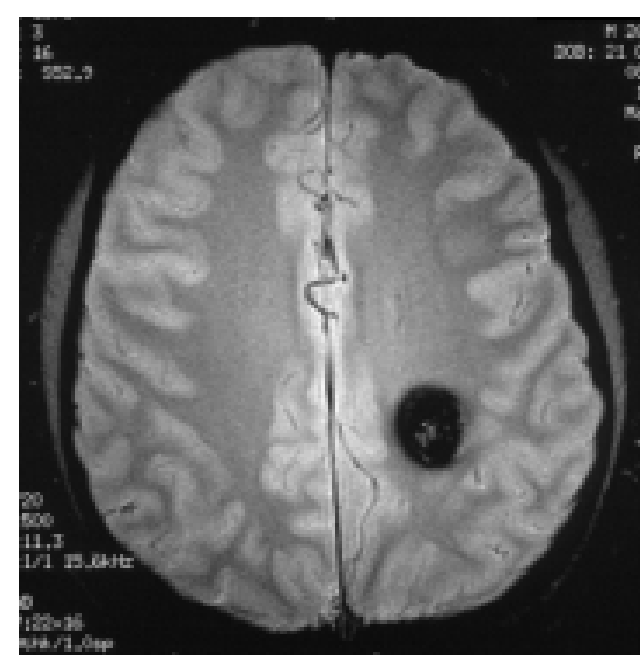

FIG. 2. Left: Axial MR image showing a left rolandic cavernous angioma. ing an associated distant venous angioma-like lesion (arrow).

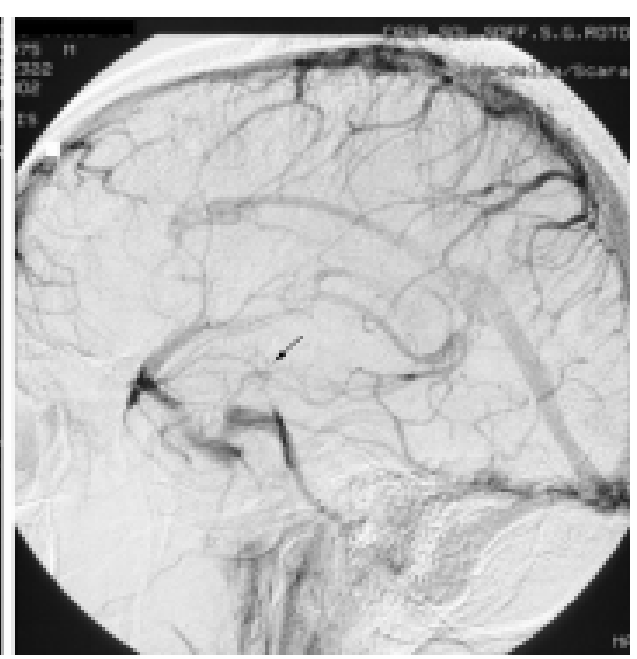

Right: Angiographic study demonstrat- 
have clinically recognizable symptoms. ${ }^{25,32,49,58}$ This supports the suggestion that the population incidence of familial cerebral CMs may be significantly underestimated.

In our experience, genetic studies were helpful in identifying mutations in seven (78\%) of nine patients with a family history of cerebral CMs; in $12(66 \%)$ of 18 patients harboring multiple cerebral CMs but with no known clinically affected relative; and, interestingly, in two (3\%) of 62 patients harboring a single, apparently sporadic lesion. Performing mutational analysis in family members, we found 40 mutation carriers and, among them, 19 with asymptomatic cerebral CMs. Our data show that mutation analysis is of striking importance for prognosis and clinical management of both apparently sporadic and familial cerebral CMs. The DNA screening protocol will change the care of familial forms of cerebral CMs, because affected asymptomatic family members may benefit by early detection of lesions, whereas the exclusion of nonmutation-carrying family members as at-risk individuals reduces the economic and psychological burden of clinical and instrumental monitoring. In relatives of patients with known familial forms of cerebral CM in whom the mutations have not been found, all family members at risk have to be monitored.

After analysis of this series of patients and a literature review, ${ }^{21,29,35,38,39,54,57,60,61}$ we developed a management algorithm to deal with supratentorial cavernomas, taking into account clinical presentation, lesion location, and genetic findings. The algorithm is as follows.

1. Asymptomatic cerebral CMs are generally observed carefully, with follow-up MR imaging performed at yearly or 2-year intervals.

2. Symptomatic (severe headache, seizures, progressive neurological deficits) cerebral CMs in noneloquent areas should be resected with the aid of frameless stereotactic guidance. In eloquent and/or deep locations, symptomatic (intractable seizures, severe or repeated hemorrhage, progressive neurological deficits) cerebral CMs should be resected with the aid of frameless stereotaxy and integrated fMR imaging studies.

3. In cases of cerebral CMs presenting with seizure, the threshold for intervention depends on lesion accessibility, eloquent location, and severity of the seizure disorder as well as drug resistance. Patients with multiple CMs should be studied extensively to decide if one or more lesions are responsible for the symptoms. In noneloquent and accessible areas, surgery should be performed to remove the lesion as soon as possible after the seizure disorder begins. In cases of temporal lobe seizures, if simple lesionectomy fails to correct the disorder, detailed cortical and electrode electroencephalographic mapping should be performed, possibly followed by epilepsy surgery (such as amygdalohippocampectomy).

4. Associated venous anomalies should be spared during surgery for cerebral CMs.

5. In suspected familial cases identified based on clinical and/or neuroimaging results, genetic analysis must be performed. In the event of positive findings on mutational analysis, the genetic study should be extended to family members, who could benefit in two ways: 1) in the event that a mutation carrier is found, by early detection of cerebral CMs; and 2) in the event that no mutation is found, by exclusion of the family member from the at-risk group. Clinical and neuroimaging monitoring should be recommended also in cases of negative findings on mutational analysis but suspicious clinical symptoms or a known family history of the disorder. When the family history is not available or is unreliable, genetic analysis should also be considered in patients harboring an apparently single, sporadic lesion to detect cryptic or de novo genetic mutation.

6 . In cases of incomplete resection, repeated surgery is advocated for cerebral CMs located in noneloquent areas, whereas in a deep and/or eloquent location, further surgery should be performed on a case-by-case basis.

7. We support the need for long-term follow-up imaging in all patients to detect recurrences or de novo lesions.

\section{Conclusions}

Surgery for supratentorial cerebral CMs in locations that are not eloquent or deep is generally safe and curative. In cerebral CMs located in deep and/or eloquent areas and accompanied by progressive neurological deficits, evidence of hemorrhage, and uncontrolled seizures, surgery performed with the aid of frameless stereotactic guidance and fMR imaging according to an integrated plan is recommended and is followed by acceptably low morbidity. Our data support the need for long-term imaging follow up in all patients, careful preoperative vascular study to detect associated venous anomalies, and the importance of genetic mutational analysis.

\section{References}

1. Aiba T, Tanaka R, Koike T, Kameyama S, Takeda N, Komata T: Natural history of intracranial cavernous malformations. J Neurosurg 83:56-59, 1995

2. Amin-Hanjani S, Ogilvy CS, Ojemann RG, Crowell RM: Risks of surgical management for cavernous malformations of the nervous system. Neurosurgery 42:1220-1228, 1998

3. Awad IA, Rosenfeld J, Ahl J, Hahn JF, Luders H: Intractable epilepsy and structural lesions of the brain: mapping, resection strategies, and seizure outcome. Epilepsia 32:179-186, 1991

4. Bergeson PS, Rekate HL, Tack ED: Cerebral cavernous angiomas in the newborn. Clin Pediatr (Phila) 31:435-437, 1992

5. Bertalanffy H, Benes L, Miyazawa T, Alberti O, Siegel AM, Sure U: Cerebral cavernomas in the adult. Review of the literature and analysis of 72 surgically treated patients. Neurosurg Rev 25:1-55, 2002

6. Bertalanffy H, Gilsbach JM, Eggert HR, Seeger W: Microsurgery of deep-seated cavernous angiomas: report of 26 cases. Acta Neurochir 108:91-99, 1991

7. Buhl R, Hempelmann RG, Stark AM, Mehdorn HM: Therapeutical considerations in patients with intracranial venous angiomas. Eur J Neurol 9:165-169, 2002

8. Cappabianca P, Alfieri A, Maiuri F, Mariniello G, Cirillo S, de Divitiis E: Supratentorial cavernous malformations and epilepsy: seizure outcome after lesionectomy on a series of $35 \mathrm{pa}-$ tients. Clin Neurol Neurosurg 99:179-183, 1997

9. Casazza M, Broggi G, Franzini A, Avanzini G, Spreafico R, Bracchi M, et al: Supratentorial cavernous angiomas and epileptic seizures: preoperative course and postoperative outcome. Neurosurgery 39:26-34, 1996

10. Clatterbuck RE, Eberhart CG, Crain BJ, Rigamonti D: Ultrastructural and immunocytochemical evidence that an incompetent blood-brain barrier is related to the pathophysiology of cavernous malformations. J Neurol Neurosurg Psychiatry 71:188-192, 2001 
11. Cohen DS, Zubay GP, Goodman RR: Seizure outcome after lesionectomy for cavernous malformations. J Neurosurg 83: 237-242, 1995

12. Craig HD, Günel M, Cepeda O, Johnson EW, Ptacek L, Steinberg GK, et al: Multilocus linkage identifies two new loci for a Mendelian form of stroke, cerebral cavernous malformation, at 7p15-13 and 3q25.2-27. Hum Mol Genet 7: 1851-1858, 1998

13. Del Curling O Jr, Kelly DL Jr, Elster AD, Craven TE: An analysis of the natural history of cavernous angiomas. J Neurosurg 75:702-708, 1991

14. Denier C, Labauge P, Brunereau L, Cave-Riant F, Marchelli F, Arnoult M, et al: Clinical features of cerebral cavernous malformations patients with KRIT1 mutations. Ann Neurol 55:213-220, 2004

15. Detwiler PW, Porter RW, Zabramski JM, Spetzler RF: De novo formation of a central nervous system cavernous malformation: implications for predicting risk of hemorrhage. Case report and review of the literature. J Neurosurg 87:629-632, 1997

16. Drayer B, Burger P, Darwin R, Riederer S, Herfkens R, Johnson GA: MRI of brain iron. AJR Am J Roentgenol 147:103-110, 1986

17. Engel J Jr, Van Ness PC, Rasmussen TB, Ojemann LM: Outcome with respect to epileptic seizures, in Engel J Jr (ed): Surgical Treatment of the Epilepsies, ed 2. New York: Raven Press, 1993, pp 609-621

18. Ferroli P, Casazza M, Marras C, Mendola C, Franzini A, Broggi G: Cerebral cavernomas and seizures: a retrospective study on 163 patients who underwent pure lesionectomy. Neurol Sci 26:390-394, 2006

19. Gomori JM, Grossman RI, Goldberg HI, Hackney DB, Zimmerman RA, Bilaniuk LT: Occult cerebral vascular malformations: high-field MR imaging. Radiology 158:707-713, 1986

20. Hsu FPK, Rigamonti D, Huhn SL: Epidemiology of cavernous malformations, in Awad IA, Barrow DL (eds): Cavernous Malformations. Park Ridge, IL: American Association of Neurological Surgeons, 1993, pp 13-23

21. Kattapong VJ, Hart BL, Davis LE: Familial cerebral cavernous angiomas: clinical and radiologic studies. Neurology 45: 492-497, 1995

22. Kim DS, Park YG, Choi JU, Chung SS, Lee KC: An analysis of the natural history of cavernous malformations. Surg Neurol 48:9-18, 1997

23. Kondziolka D, Lunsford LD, Kestle JRW: The natural history of cerebral cavernous malformations. J Neurosurg 83: 820-824, 1995

24. Krayenbuhl H, Siebenmann R: Small vascular malformations as a cause of primary intracerebral hemorrhage. J Neurosurg 22: 7-20, 1965

25. Labauge $P$, Laberge $S$, Brunereau L, Levy C, Tournier-Lasserve E: Hereditary cerebral cavernous angiomas: clinical and genetic features in 57 French families. Sociéte Française de Neurochirurgie. Lancet 352:1892-1897, 1998

26. Lange SC, Neafsey EJ, Wyler AR: Neuronal activity in chronic ferric chloride epileptic foci in cats and monkey. Epilepsia 21:251-254, 1980

27. Larson JJ, Ball WS, Bove KE, Crone KR, Tew JM Jr: Formation of intracerebral cavernous malformations after radiation treatment for central nervous system neoplasia in children. J Neurosurg 88:51-56, 1998

28. Mao Y, Zhou L, Du G, Chen L: Image-guided resection of cerebral cavernous malformations. Chin Med J (Engl) 116: 1480-1483, 2003

29. Maraire JN, Awad IA: Intracranial cavernous malformations: lesion behavior and management strategies. Neurosurgery 37: 591-605, 1995

30. Margolis G, Odom GL, Woodhall B: Further experiences with small vascular malformations as a cause of massive intracranial bleeding. J Neuropathol Exp Neurol 20:161-167, 1961
31. Margolis G, Odom GL, Woodhall B, Bloor BM: The role of small angiomatous malformations in the production of intracerebral hematomas. J Neurosurg 8:564-575, 1951

32. Mathiesen T, Edner G, Kihlström L: Deep and brainstem cavernomas: a consecutive 8-year series. J Neurosurg 99:31-37, 2003

33. McCormick WF: The pathology of vascular ("arteriovenous") malformations. J Neurosurg 24:807-816, 1966

34. McCormick WF, Nofzinger JD: "Cryptic" vascular malformations of the central nervous system. J Neurosurg 24:865-875, 1966

35. Moriarity JL, Wetzel M, Clatterbuck RE, Javedan S, Sheppard JM, Hoenig-Rigamonti K, et al: The natural history of cavernous malformations: a prospective study of 68 patients. Neurosurgery 44:1166-1173, 1999

36. New PF, Ojemann RG, Davis KR, Rosen BR, Heros R, Kjellberg RN, et al: MR and CT of occult vascular malformations of the brain. AJR Am J Roentgenol 147:985-993, 1986

37. Noto S, Fujii M, Akimura T, Imoto H, Nomura S, Kajiwara K, et al: Management of patients with cavernous angiomas presenting epileptic seizures. Surg Neurol 64:495-498, 2005

38. Ojemann RG, Crowell RM, Ogilvy CS: Management of cranial and spinal cavernous angiomas (honored guest lecture). Clin Neurosurg 40:98-123, 1993

39. Ojemann RG, Ogilvy CS: Microsurgical treatment of supratentorial cavernous malformations. Neurosurg Clin N Am 10: 433-440, 1999

40. Otten P, Pizzolato GP, Rilliet B, Berney J: [131 cases of cavernous angioma (cavernomas) of the CNS, discovered by retrospective analysis of 24, 535 autopsies.] Neurochirurgie 35:82-83, 128-131, 1989 (Fr)

41. Pollock BE, Garces YI, Stafford SL, Foote RL, Schomberg PJ, Link MJ: Stereotactic radiosurgery for cavernous malformations. J Neurosurg 93:987-991, 2000

42. Porter PJ, Willinsky RA, Harper W, Wallace MC: Cerebral cavernous malformations: natural history and prognosis after clinical deterioration with or without hemorrhage. J Neurosurg 87:190-197, 1997

43. Rabinov JD: Diagnostic imaging of angiographically occult vascular malformations. Neurosurg Clin N Am 10:419-432, 1999

44. Ramina R, Ingunza W, Vonofakos D: Cystic cerebral cavernous angioma with dense calcification. Case report. J Neurosurg 52:259-262, 1980

45. Raychaudhuri R, Batjer HH, Awad AI: Intracranial cavernous angioma: a practical review of clinical and biological aspects. Surgical Neurology 63:319-328, 2005

46. Requena I, Arias M, Lopez-Ibor L, Pereiro I, Barba A, Alonso A, et al: Cavernomas of the central nervous system: clinical and neuroimaging manifestations in 47 patients. J Neurol Neurosurg Psychiatry 54:590-594, 1991

47. Rigamonti D, Drayer BP, Johnson PC, Hadley MN, Zabramski J, Spetzler RF: The MRI appearance of cavernous malformations (angiomas). J Neurosurg 67:518-524, 1987

48. Rigamonti D, Hadley MN, Drayer BP, Johnson PC, HoenigRigamonti K, Knight JT, et al: Cerebral cavernous malformations. Incidence and familial occurrence. N Engl J Med 319: 343-347, 1988

49. Robinson JR, Awad IA: Clinical spectrum and natural course, in Awad IA, Barrow DL (eds): Cavernous Malformations. Park Ridge, IL: American Association of Neurological Surgeons, 1993, pp 25-36

50. Robinson JR, Awad IA, Little JR: Natural history of the cavernous angioma. J Neurosurg 75:709-714, 1991

51. Roda JM, Carceller F, Perez-Higueras A, Morales C: Encapsulated intracerebral hematomas: a defined entity. Case report. J Neurosurg 78:829-833, 1993

52. Roob G, Fazekas F: Magnetic resonance imaging of cerebral microbleeds. Curr Opin Neurol 13:69-73, 2000 
53. Russel DS, Rubenstein LJ: Pathology of Tumors of the Nervous System, ed 5. Baltimore: Williams \& Wilkins, 1989, pp 730-736

54. Simard JM, Garcia-Bengochea F, Ballinger WE Jr, Mickle JP, Quisling RG: Cavernous angioma: a review of 126 collected and 12 new clinical cases. Neurosurgery 18:162-172, 1986

55. Steinberg GK, Chang SD, Gewirtz RJ, Lopez JR: Microsurgical resection of brainstem, thalamic, and basal ganglia angiographically occult vascular malformation. Neurosurgery 46: 260-271, 2000

56. Sure U, Butz N, Schlegel J, Siegel AM, Wakat JP, Mennel HD, et al: Endothelial proliferation, neoangiogenesis, and potential de novo generation of cerebrovascular malformations. J Neurosurg 94:972-977, 2001

57. Tagle P, Huete I, Méndez J, del Villar S: Intracranial cavernous angioma: presentation and management. J Neurosurg 64: 720-723, 1986

58. Tomlinson FH, Houser OW, Scheithauer BW, Sundt TM Jr, Okazaki H, Parisi JE: Angiographically occult vascular malformations: a correlative study of features on magnetic resonance imaging and histological examination. Neurosurgery 34: 792-800, 1994
59. Vives KP, Awad IA: Overview: vascular causes of epilepsy, in Kotagal P, Lüders H (eds): The Epilepsies: Etiologies and Prevention. New York: Academic Press, 1999, pp 371-383

60. Voigt K, Yaşargil MG: Cerebral cavernous haemangiomas or cavernomas. Incidence, pathology, localization, diagnosis, clinical features and treatment. Review of the literature and report of an unusual case. Neurochirurgia (Stuttg) 19:59-68, 1976

61. Wilkins RH: Natural history of intracranial vascular malformations: a review. Neurosurgery 16:421-430, 1985

62. Zabramski JM, Wascher TM, Spetzler RF, Johnson B, Golfinos J, Drayer BP, et al: The natural history of familial cavernous malformations: results of an ongoing study. J Neurosurg 80: 422-432, 1994

Manuscript received May 11, 2006.

Accepted in final form May 30, 2006.

Address reprint requests to: Vincenzo Antonio D'Angelo, M.D., Neurosurgical Unit, Neuromed Institute, "Casa Sollievo della Sofferenza”, Viale Cappuccini, 71013 San Giovanni Rotondo (FG), Italy.email: v.dangelo@operapadrepio.it. 